\title{
Risk Management Software Utilization in the Singapore Construction Industry: Evaluation and Improvement
}

\author{
Bon-Gang Hwang ${ }^{1}$ and Pee Mee Chua $^{2}$
}

\begin{abstract}
Risk management is popularly and widely used in various industries to handle uncertainty that can negatively affect their businesses. While in the current Information-Technology oriented age, software packages are designed to assist in carrying out risk management processes, the construction industry does not seem to have software that is tuned to its specific characteristics and processes. Therefore, this study first explores the types of software that are commonly used for risk management in the Singapore construction industry. Also, using one-sample t-test, it is tested if the software programs used in the construction industry have effectively catered the needs of the users. For the analysis, a survey questionnaire was developed and the representatives from 34 companies participated in the survey. Furthermore, this study also makes use of the current risk management framework defined in ISO31000 to design a risk management software algorithm that can suit the needs for the Singapore construction industry. The results from this study will contribute to identifying strategic areas, in terms of use of risk management software, on which the industry needs to focus, ultimately enhancing their performance of risk management.
\end{abstract}

Keywords: Risk Management, Software, Construction Project, Project Management, Singapore

\section{INTRODUCTION}

In today's competitive and unpredictable circumstances, risk management is highly emphasized and utilized in businesses and projects in various industries. The Risk Management Survey 2006 conducted by KPMG (2006) reported that risk management has become an increasingly important area that organizations in Singapore should focus on. The reason for the increase may be due to some major events such as the outbreak of Severe Acute Respiratory Syndrome (SARS) virus in 2003, the Asian Tsunami in 2004 and the current economic crisis. Risk management usually involves the process of identifying potential risks, assessing their criticality which is combination of probabilities and impacts, and developing strategies mitigating and manage them.

According to Loosemore et al. (2006), most construction projects encounter greater difficulties in identifying, assessing and managing risks than projects performed by other industries, due to the rapid increase in complexity of construction projects. While it is a great challenge to effectively manage all possible risks, the rewards from effective risk management can be titanic. "The more confident a company is in its risk management systems, the more likely it is to secure work at a lower price than its competitors, and more likely to turn risks into opportunities to make profit" (Loosemore et al. 2006). Additionally, effective risk management helps to build a positive reputation for the company in the long run.

With the current dramatic evolvement in Information Technology (IT), efficiency in managing risks can be improved. According to Roland (2008), with the aid of technology, "companies can more easily incorporate risk management into critical business processes and improve performance." He has also identified and described the key features of technology employed in mature risk management program. These key features include: (1) collaborative process support; (2) audit and security; (3) proactive automation; and (4) integration with performance management.

In order to make use of the advantages of IT, many software programs, suites and packages are developed to support the risk management processes for project management and businesses. As a result, this study aims to explore and analyze the suitability and effectiveness of the available software used for risk management in the Singapore construction industry. More specific objectives are: (1) to identify the most commonly used software; (2) to explore effectiveness of the software; and (3) to suggest a risk management software algorithm to be able to better suit the Singapore construction industry.

\section{BACKGROUND}

A. Risk Management Framework vs. Risk Management Information System (RMIS)

An effective risk management framework must be developed before implementing a RMIS in an organization (Heather et al. 2005). As the needs of the RMIS will be clearly defined in the framework, accurate decisions then can be made to address them. Heather et al. (2005)

\footnotetext{
${ }^{1}$ Assistant Professor, National University of Singapore, S117566, Singapore, bdghbg@nus.edu.sg (*Corresponding Author)

${ }^{2}$ Property Executive, Property inc.Pte. Ltd., S150167.
} 
defined the risk management framework as "the processes, and the order and timing of the processes that will be used to manage risks." They also identified that the principles of this framework are to change from a/an:

[1] Fragmented information management to an integration of all the data within a single database

[2] Ad hoc approach with no formal structure to a continuous, customized risk management approach

[3] Narrow focus where each operation concentrates only on its own risks to a broad focus where the entire organization manages its risks in concert

[4] Spreadsheet approach where only one aspect of the organization's risk is ever considered to a financial intelligence approach where all aspects of risks are considered equally

B. Roles: Risk Management Information System (RMIS) vs. Risk Management Software (RMS)

Tweedy (1990) agreed that Risk Management Information System (RMIS) can help in the aspect of "claims management and administration for all property/casualty lines, loss development and forecasting, cost of risk allocation, financial modeling, policy registration, litigation management and exposure analysis". Olsen (1995) also stated that risk managers have used RMIS to identify and analyze a range of risks that could interrupt their working operations, and a set of actions procedure can be developed before hand to mitigate these risks. Furthermore, some RMIS can also be used to: (1) track information related to a variety of risks on a global basis; (2) audit management procedure; and (3) generate reports and facilitate information sharing with other departments and industry groups for benchmarking. As such, RMIS plays an important role in ensuring the effectiveness and efficiencies of risk management.

Tan (2008) stated that Information System (IS) usually means the application of IT to business and society, and it is made up of five components which are: (1) the hardware used in the system; (2) the software that is used to control the hardware and how it is used in the system; (3) the people who use the system; (4) work procedure that guide the people on how to use the system; and (5) data that is captured, stored and processed by the system. As software is one of the important components that are vital to create an effective IS, Risk Management Software (RMS) will play a critical role in RMIS.

In general, RMS is a component in the suite of project management software packages that are commercially available in the market. The design of RMS packages is mostly based on network technique and critical path method. RMS is usually used for appraising the risk incurred in projects. Moreover, RMS will assist the decision-maker to manage projects which may be subjected to incalculable uncertainty in the unstable environment, throughout the whole project lifecycle. Loosemore et al. (2006) also argued that as there is a large amount of data being generated on the project in the swiftly changing business environment, RMS is needed as a management system that can record, store, organize and facilitate rapid access to risk-related information. Additionally, when RMS is used appropriately, it can be a valuable tool to assist in risk analysis and manage the risks and opportunities of the project effectively.

\section{Benefits and Challenges of Risk Management Software (RMS)}

RMS provides a more flexible and greater control of data, simplifying or automating some of the risk management processes (Roland 2008). Additionally, RMS users may have a better access to more accurate and useful risk management information which produces better operating results. According to Smith et al. (2006), RMS is beneficial for both risk managers and modelers, as it has speeded the performance and reduces the complexity of running complicated and iterative calculations in project risk modeling and simulation. Furthermore, it can also create a flexible way of modeling data during risk management processes, and will present quantitative and better graphical outputs for easier understanding of the results obtained from the risk modeling and simulation.

On the contrary, Duden (1996) identified several challenges for employing RMS. One of the most critical challenges was "experiencing frustration" from a large selection of software available in the market. This is because the selection requires for users to make a decision on a compatible RMS offering right solutions for their needs. Even organizations that retain consultants to evaluate potential candidates of RMS can easily waste a great deal of effort and expense trying to select a best solution. Another challenge is that many software developers have difficulties in understanding the needs of the customer while they may spend incredible amount of time and effort to design and develop the software. Smith et al. (2006) also reported the following disadvantages of RMS that should not be underestimated when its adoption is considered:

- The functions and methods used for analysis are programmed based on assumptions and thus some of them will not meet the users' needs and requirements.

- Not accurate enough to reflect the actual results and reaction of the real life project, as the model produced in risk analysis is only a mathematical representation of the real life situation.

- The challenge and time to select the most appropriate RMS package to suit the actual user needs.

- The time, effort and money spent to master the RMS.

Too complicate to $\mathrm{u}$

\section{Types of Risk Management Software (RMS)}

Loosemore et al. (2006) divided RMS into two major categories: (1) risk management information system software; and (2) risk analysis software. More details of the categories are discussed in the subsequent sections. 


\section{1) Risk Management Information System Software (RMISS)}

RMISS is designed to provide a more general means to support the entire risk management system as well as a mechanism for collecting and disseminating data for reliable risk analysis. Furthermore, it allows users to have easy access to critical performance data that can be used for reporting to management and stakeholders. RMISS is mainly divided into two types: (1) process driven; and (2) information driven. Process driven software is designed with a logical process program that will aid decision-makers. The quality of the process programmed in this software will be a great concern when choosing which software is to be employed for risk management. On the other hand, information driven software is generally composed of a database which stores risk related information that can be accessed by risk managers. The quality of the database design along with the presenting and reporting tools are important criteria when selecting this type of software.

\section{2) Risk Analysis Software}

Loosemore et al. (2006) defined risk analysis software as a tool to overcome the complexity and tedium that are often contained in quantitative risk analysis process. They identified four main types of risk analysis software in the current market.

The first type of software is the custom-designed product, which is designed and fitted into the in-house project management system of companies. The second type is add-in software integrated into the spreadsheet programs that many companies use for their risk analyses. These add-ins are usually cheaper and cost around USD\$100 to USD\$300 per user (Leslie, 1995). An example of this type of add-in program is @ Risk designed by Pailsade, which links to an Excel program like Lotus 123. Also, several spreadsheet packages, which employ Monte-Carlo simulation techniques to calculate the costs of undertaken projects or making decisions that are subject to uncertainty, were classified by Smith et al. (2006).

The third type of software is large off-the-shelf packages such as ARTEMIS and PRIMAVERA. They are usually based on project management system that is already in place. These powerful tools enable users to make probabilistic inputs to network activities to deal with both time and costs, and sometimes for correlation analysis too. However, this type of software may be too difficult to be employed due to its complexity and various requirements (e.g., a critical path must be setup before employing this type of software for risk analysis), which are not always appropriate for small and simple projects. Furthermore, Leslie (1995) stated that these programs are more expensive as compared to the add-ins.

The last type of software is a stand-alone product, which includes project management tools. This type of product is usually developed by risk consultant/specialist, not by software or project management sales. As a result, it is rather expensive and usually requires specific training in utilizing this software. The hybrid package identified by Smith et al. (2006) has similar characteristics to this stand-alone product. This package is tools designed for specialized application that employs complex statistical methods like discontinuous logic mapping, data envelop analysis and fragility analysis.

\section{E. Risk Management Software Classification}

The research conducted by Noakes-Fry (2003) investigated 12 major risk management software programs, which are commonly used by risk management personnel. They are: (1) @ RISK; (2) Buddy System; (3) Consolidated Omnibus Budget Reconciliation Act; (4) Crystal Ball; (5) DATA Interactive; (6) DecisionPro; (7) Enterprise Risk Assessor; (8) MARION; (9) Ris3; (10) RiskWatch; (11) DeclareInc; and (12) Omsight ConsultingLtd. These software programs were classified based on whether the software is independent or add-in, what risk assessment tools are available to perform quantitative and qualitative analyses, and what industry the software is designed for. More details of each of the software listed above can be found in the research report by Noakes-Fry (2003).

\section{METHODOLOGY}

\section{A. Data Collection}

A survey was conducted to explore: (1) the types of RMS employed by construction companies in Singapore; and (2) how they rate the effectiveness of the RMS. The questionnaires used for the survey were sent out to 250 registered contractors and licensed builders listed in the Building and Construction Authority (BCA) website. Further description of the questionnaire is presented later in Section C.

After the results from the survey were analyzed, interviews were carried out with some of the industry experts who participated in the survey. The interviewees provided their opinions on the survey results, specifying why they think the results came out.

\section{B. Survey Sample}

The target of the survey was industry experts who had the experience in conducting risk management for construction projects and who are currently holding managerial positions in project management, site management, risk and safety management, and operation management in the registered contractors and licensed builders firms in Singapore. A total number of 34 experts responded to the survey.

\section{Survey Questionnaire}

The questionnaire consisted of three sections. The first section contained the questions capturing the profile 
of the respondents. In the second section, whether the respondents have the experience in conducting risk management for construction projects was asked, followed by the question asking which processes of risk management they have performed. The risk management processes were identified according to the risk management standard terms defined in ISO31000. ISO31000 is a guide and framework, which can be used by any organization, for implementing process, terminology, and other best practices for risk management (Shortreed, 2008). The last section included questions asking: (1) what software they use for each of the risk management processes; (2) the level of effectiveness of the software used; (3) the level of satisfaction with the software used; and (4) the level of importance of the software selection criteria.

\section{Data Analysis}

The responses from the survey were analyzed using Statistical Package for Social Sciences (SPSS) software. To evaluate the effectiveness of the software used, onesample t-tests were performed. The one-sample t-test can be used to see if a sample mean significantly differs from a hypothesized or specific value (Garson, 2008).

\section{DATA ANALYSIS AND DISCUSSIONS}

\section{A. Data Presentation}

A total of 34 completed questionnaires were retuned. The profile of the respondents and theirs companies is presented in Table 1.
The largest group of the respondents was project managers $(55.88 \%)$, followed by directors of their companies (20.59\%). The number of years the respondents have worked in the construction industry was divided into four categories (less than 1 year, 1 to 10 years, 11 to 20 years and more than 20 years) and the most representative group was 1 to 10 (38.24\%), followed by the group between 11 and 20 years $(32.35 \%)$. Also, each respondent could report more than one type of projects that they have involved in. The result showed that a higher percentage of the companies involved in residential projects $(37.7 \%)$, followed by commercial projects $(24.59 \%)$. The majority of the companies have the head-count of less than or equal to $50(82.35 \%)$.

TABLE 1

PROFILE OF COMPANIES AND RESPONDENTS SURVEYED

\begin{tabular}{|c|c|c|c|c|}
\hline \multicolumn{3}{|c|}{ Category } & Frequency & Percentage \\
\hline \multirow{11}{*}{$\begin{array}{l}\text { Companies' } \\
\text { Profile }\end{array}$} & \multirow{7}{*}{$\begin{array}{l}\text { Key projects that } \\
\text { the companies } \\
\text { involved in }\end{array}$} & Residential & 23 & $37.70 \%$ \\
\hline & & Residential with Commercial & 7 & $11.48 \%$ \\
\hline & & Commercial & 15 & $24.59 \%$ \\
\hline & & Industrial & 14 & $22.95 \%$ \\
\hline & & Pre-casting & 1 & $1.64 \%$ \\
\hline & & Finishes & 1 & $1.64 \%$ \\
\hline & & Total & 61* & $100.00 \%$ \\
\hline & \multirow{4}{*}{$\begin{array}{l}\text { Number of full-time } \\
\text { employees in the } \\
\text { company }\end{array}$} & Less than or equal to 50 & 28 & $82.35 \%$ \\
\hline & & 51 to 250 & 5 & $14.71 \%$ \\
\hline & & 251 to 500 & 1 & $2.94 \%$ \\
\hline & & Total & 34 & $100.00 \%$ \\
\hline \multirow{11}{*}{$\begin{array}{c}\text { Respondents' } \\
\text { Profile }\end{array}$} & \multirow{6}{*}{$\begin{array}{l}\text { Designation of the } \\
\text { interviewee }\end{array}$} & Director & 7 & $20.59 \%$ \\
\hline & & Operation Manager & 3 & $8.82 \%$ \\
\hline & & Project Manager & 19 & $55.88 \%$ \\
\hline & & Site Manager & 3 & $8.82 \%$ \\
\hline & & Risk Officer & 2 & $5.88 \%$ \\
\hline & & Total & 34 & $100.00 \%$ \\
\hline & \multirow{5}{*}{$\begin{array}{l}\text { Number of years } \\
\text { the interviewees } \\
\text { worked in the } \\
\text { construction } \\
\text { industry }\end{array}$} & Less than 1 year & 4 & $11.76 \%$ \\
\hline & & 1 to 10 years & 13 & $38.24 \%$ \\
\hline & & 11 to 20 years & 11 & $32.35 \%$ \\
\hline & & More than 20 years & 6 & $17.65 \%$ \\
\hline & & Total & 34 & $100.00 \%$ \\
\hline
\end{tabular}

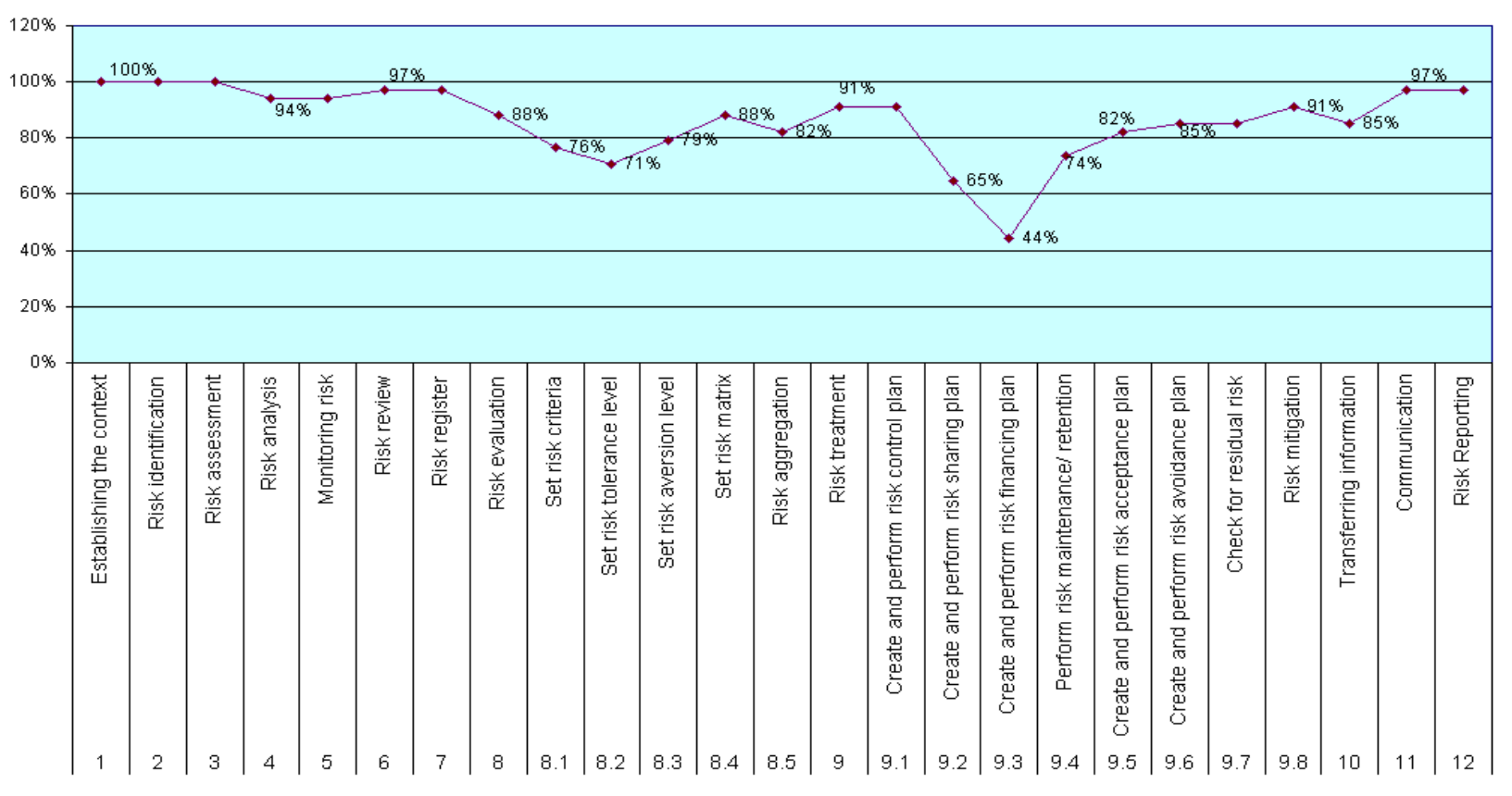

FIGURE 1

Risk Management Processes Performed 


\section{B. Risk Management Processes Preformed}

As seen in Figure 1, all the respondents have experience in developing plans for risk management (establishing context), identifying risks, and assessing the impacts of risks. This result might be due to the Workplace Safety and Health (Risk Management) Regulations taken effect on 1 September 2006, encouraging the companies involved in the construction industry to conduct risk planning, identification, and assessment for their projects (Ministry of Manpower, 2006). Furthermore, $97 \%$ of the respondents have carried out risk review, risk register, risk communication, and risk reporting and presentation while $94 \%$ of the respondents have conducted risk analysis and risk monitoring. Also, many of the respondents ranging from $65 \%$ to $91 \%$ responded that they have performed the rest of the risk management processes for their construction projects. It is of interest that only $44 \%$ of the respondents have experience in developing risk financing plans. This might be due to the lack of organizational efforts made for allocating specific budget to risk management.

\section{Use of Software for Risk Management Processes}

As summarized in Figure 2, 100\% of the respondents have performed, with the aid of software, the risk management processes of context establishment, risk identification, risk assessment, risk review, risk register, risk communication, and risk reporting and presentation.
Also, $97 \%$ of the respondents have used software to carry out risk analysis and risk monitoring while $94 \%$ of them. Similar to the result of the analysis discussed in the previous section, the majority of the respondents have used software to aid in carrying out all the risk management processes, except creating a risk financing plan.

\section{Effectiveness of Risk Management Software}

After the respondents rated the effectiveness of using software for managing each of the risk management processes, the data were collated and analyzed by the one-sample t-test, using the SPSS software. The constant hypothesized value $(\mu)$ was set at ' 5 ', which was the test value as well as the median of the nine-point scale with ' 1 being very ineffective and ' 9 ' being very effective. ' 5 ' also indicates that using software was neither effective nor ineffective.

Table 2 presents the top five risk management processes where using software can be effective. Based on the p-values from the t-tests, it can be concluded that the sample means are significantly different from the constant hypothesized value $(\mu)$ of 5 . This indicates that the respondents considered using software for these five processes effective.

Furthermore, Table 3 summarizes the distribution of different types of software used for the top 5 processes.

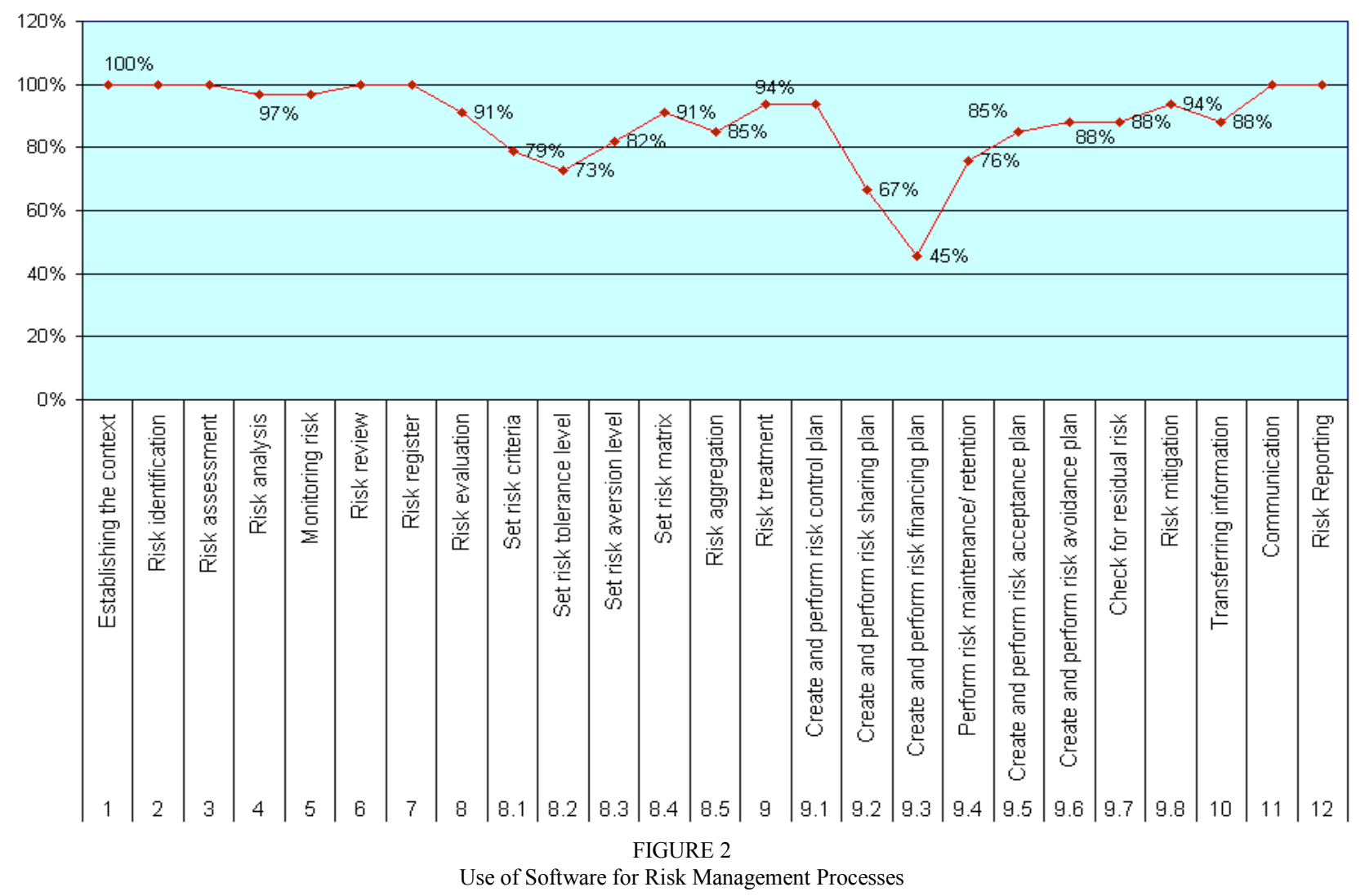


A majority of the respondents used Microsoft Excel for all the risk management processes. This may imply that Microsoft Excel spreadsheet software is widely employed in the local construction industry. One possible reason for this is that spreadsheet software can simulate and automate tasks that involve recording data and information, and repetitive numeric calculations. (Beekman \& Quinn, 2008). Another reason can be the user-friendly interface of Microsoft Excel, which provides powerful tools and features for analyzing, sharing, creating and managing data with ease (Protusada, 2008).

TABLE 2

TOP 5 PRoCESSES EFFECTIVELY MANAGED By SOFTWARE

\begin{tabular}{|c|c|c|c|c|c|}
\hline \multirow{2}{*}{$\begin{array}{c}\text { Risk Management } \\
\text { Processes }\end{array}$} & Mean & T-value & $\begin{array}{c}\text { Mean } \\
\text { Difference }\end{array}$ & $\begin{array}{c}\text { Degrees of } \\
\text { Freedom }\end{array}$ & P-value \\
\cline { 2 - 6 } & 6.6364 & 8.05 & 1.63636 & 32 & 0.000 \\
\hline Risk assessment & 6.5758 & 12.049 & 1.57576 & 32 & 0.000 \\
\hline Establishing the context & 6.4545 & 5.575 & 1.45455 & 21 & 0.000 \\
\hline $\begin{array}{c}\text { Create \% perform risk } \\
\text { sharing plan }\end{array}$ & 6.4242 & 8.441 & 1.42424 & 32 & 0.000 \\
\hline Risk identification & 6.2121 & 10 & 1.21212 & 32 & 0.000 \\
\hline Risk Reporting & & & & & \\
\hline
\end{tabular}

TABLE 3

TYPES OF SOFTWARE USED FOR THE TOP 5 PROCESSES

\begin{tabular}{|c|c|c|c|c|c|c|c|}
\hline $\begin{array}{c}\text { Risk Management } \\
\text { Processes }\end{array}$ & $\begin{array}{c}\text { Microsoft } \\
\text { Excel }\end{array}$ & $\begin{array}{c}\text { Microsoft } \\
\text { Words }\end{array}$ & $\begin{array}{c}\text { Microsoft } \\
\text { Powerpoint }\end{array}$ & DecisionPro & @Risk & Crystal Ball & Total \\
\hline Risk assessment & 29 & 2 & 0 & 1 & 5 & 1 & 38 \\
\hline$\%$ & $76.32 \%$ & $5.26 \%$ & $0.00 \%$ & $2.63 \%$ & $13.16 \%$ & $2.63 \%$ & $100 \%$ \\
\hline $\begin{array}{c}\text { Establishing the } \\
\text { context }\end{array}$ & 27 & 6 & 0 & 1 & 0 & 1 & 35 \\
\hline$\%$ & $77.14 \%$ & $17.14 \%$ & $0.00 \%$ & $2.86 \%$ & $0.00 \%$ & $2.86 \%$ & $100 \%$ \\
\hline $\begin{array}{c}\text { Create \& perform } \\
\text { risk sharing plan }\end{array}$ & 22 & 2 & 0 & 0 & 0 & 0 & 24 \\
\hline$\%$ & $91.67 \%$ & $8.33 \%$ & $0.00 \%$ & $0.00 \%$ & $0.00 \%$ & $0.00 \%$ & $100 \%$ \\
\hline Risk identification & 24 & 8 & 1 & 1 & 2 & 1 & 37 \\
\hline$\%$ & $64.86 \%$ & $21.62 \%$ & $2.70 \%$ & $2.70 \%$ & $5.41 \%$ & $2.70 \%$ & $100 \%$ \\
\hline Risk Reporting & 19 & 4 & 9 & 1 & 5 & 1 & 39 \\
\hline$\%$ & $48.72 \%$ & $10.26 \%$ & $23.08 \%$ & $2.56 \%$ & $12.82 \%$ & $2.56 \%$ & $100 \%$ \\
\hline
\end{tabular}

Table 4 shows the bottom five risk management processes with the five lowest means in terms of the effectiveness of using software. The t-test results revealed that using software for creating and performing risk avoidance plans, setting risk aversion level, and creating and performing risk control plans would not be effective with the statistical significance at the 0.05 level. However, the effectiveness of using software to perform risk maintenance/retention and to set risk tolerance level could not be determined as their means were not statistically different from ' 5 '.

Table 5 presents the distribution of different types of software used for the three processes. Similar to the result for the top 5 processes, a majority of the respondents have used Microsoft Excel for the three processes. Combining the result presented in Table 4, it can be concluded that although the industry experts use Microsoft Excel to develop and perform risk avoidance plans, set risk aversion level, and create and perform risk control plans, the software is not effective to manage the processes. Therefore, more comprehensive and industryspecified software for managing these processes should be studied and developed.

TABLE 4

BotTom 5 Processes EFFECTIVEly MANAGED By SOFTWARE

\begin{tabular}{|c|c|c|c|c|c|}
\hline \multirow[b]{2}{*}{$\begin{array}{l}\text { Risk Management } \\
\text { Processes }\end{array}$} & \multicolumn{5}{|c|}{ Test Value $=5$} \\
\hline & Mean & T-value & $\begin{array}{c}\text { Mean } \\
\text { Difference }\end{array}$ & $\begin{array}{l}\text { Degrees of } \\
\text { Freedom }\end{array}$ & P-value \\
\hline $\begin{array}{l}\text { Create and perform risk } \\
\text { avoidance plan }\end{array}$ & 4.2759 & -4.23 & -0.72414 & 28 & 0.000 \\
\hline Set risk aversion level & 4.2963 & -2.823 & -0.7037 & 26 & 0.009 \\
\hline $\begin{array}{c}\text { Create and perform risk } \\
\text { control plan }\end{array}$ & 4.4194 & -2.154 & -0.58065 & 30 & 0.039 \\
\hline $\begin{array}{l}\text { Perform risk maintenance/ } \\
\text { retention }\end{array}$ & 4.8 & -0.84 & -0.2 & 24 & 0.409 \\
\hline Set risk tolerance level & 4.875 & -0.485 & -0.125 & 23 & 0.632 \\
\hline
\end{tabular}

TABLE 5

TyPeS OF SOFTWARE USED FOR THE BOTTOM 3 PROCESSES

\begin{tabular}{|c|c|c|c|c|c|c|c|}
\hline $\begin{array}{c}\text { Risk Management } \\
\text { Processes }\end{array}$ & $\begin{array}{c}\text { Microsoft } \\
\text { Excel }\end{array}$ & $\begin{array}{c}\text { Microsoft } \\
\text { Words }\end{array}$ & $\begin{array}{c}\text { Microsoft } \\
\text { PowerPoint }\end{array}$ & DecisionPro & @Risk & $\begin{array}{c}\text { Crystal } \\
\text { Ball }\end{array}$ & Total \\
\hline $\begin{array}{c}\text { Create and perform risk } \\
\text { avoidance plan }\end{array}$ & 29 & 2 & 0 & 0 & 0 & 0 & 31 \\
\hline$\%$ & $93.55 \%$ & $6.45 \%$ & $0.00 \%$ & $0.00 \%$ & $0.00 \%$ & $0.00 \%$ & $100 \%$ \\
\hline Set risk aversion level & 22 & 0 & 0 & 1 & 5 & 1 & 29 \\
\hline$\%$ & $75.86 \%$ & $0.00 \%$ & $0.00 \%$ & $3.45 \%$ & $17.24 \%$ & $3.45 \%$ & $100 \%$ \\
\hline $\begin{array}{c}\text { Create and perform risk } \\
\text { control plan }\end{array}$ & 30 & 1 & 0 & 0 & 0 & 0 & 31 \\
\hline$\%$ & $96.77 \%$ & $3.23 \%$ & $0.00 \%$ & $0.00 \%$ & $0.00 \%$ & $0.00 \%$ & $100 \%$ \\
\hline
\end{tabular}

\section{E. Satisfaction Level and Selection Criteria}

Next, the respondents' overall satisfactory level of the risk management software was investigated. The result reported that a majority of the respondents (79\%) tended to be either satisfied or very satisfied with the software that they used while $21 \%$ of the respondents were dissatisfied. The reasons given for the dissatisfaction were: (1) user-unfriendly Graphical User Interface (GUI); (2) functions that do not meet users' needs; and (3) inflexibility and tediousness.

The respondents also ranked the criteria for selection of risk management software, which include userfriendliness, fit-for-purpose, functionality, cost, reliability, maturity, reporting, and stability of the vendors. The respondents reported that the most important selection criteria would be user friendliness (48.48\%), fit-for-purpose $(30.30 \%)$ and cost $(21.21 \%)$, indicating that the user friendliness aspect must be taken with significant considerations when risk management software is designed and developed.

\section{ENHANCEMENT OF RISK MANAGEMENT SOFTWARE UTILIZATION}

\section{A. An Improved Risk Management Software Algorithm}

To enhance the utilization of risk management software, it is required to incorporate risk factors specific to the construction industry with proper risk assessment algorithms. The algorithm proposed in Figure 3 is to link up each and every risk management process to enhance the flow of data and information required for risk management. The flow starts from establishing the context of the construction projects, which includes both 
external and internal context, risk management process context and risk criteria. Then, the established context becomes the basis for risk assessment. Here, risks relevant to the objectives are identified, analyzed and evaluated. Next, the impact of the risks is analyzed with quantitative and qualitative analytical techniques. According to Noakes-Fry (2003), quantitative analytical techniques can include probability distribution, scenario analysis, sensitivity analysis and stress analysis while qualitative analytical techniques include qualitative queries and surveys, model templates and reference databases, and expert system.

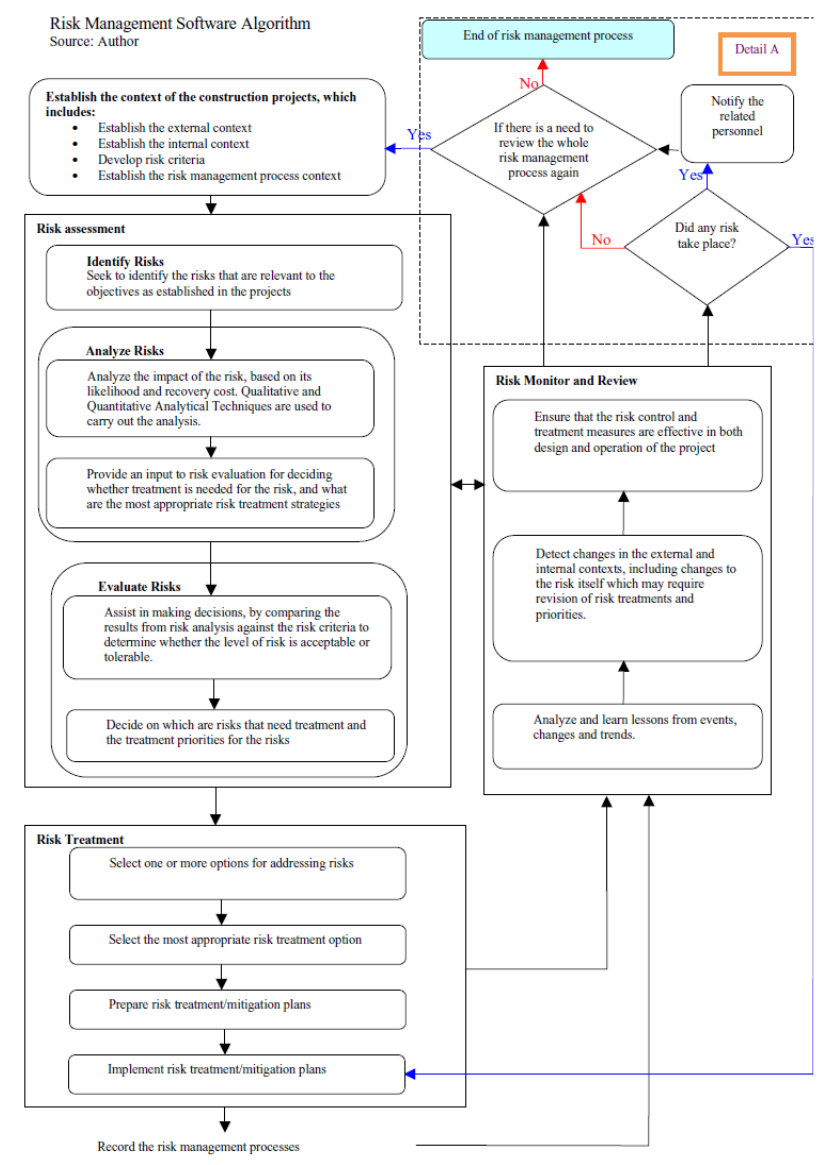

FIGURE 3

RISK MANAGEMENT SOFTWARE ALGORITHMS

Risks are then evaluated by comparing the results from risk analysis against the risk criteria to determine whether the level of risk is acceptable or tolerable. Furthermore, decision on which are the risks that need treatment and the treatment priorities for the risks are made. Following the decision-making process, the most appropriate risk treatment options are selected for addressing the risks, and treatment or mitigation plans are prepared and implemented. After these risk management processes are documented, all the risks associated in all the risk management processes are finally monitored, controlled and reviewed.
As labeled in Figure 3, Detail A shows the algorithm of how the enhanced risk management software works for situation when a monitored risk has taken place. The algorithm is illustrated by a scenario of an accident that happened at the construction site. When an accident occurred onsite, the first action that the software takes immediately is to activate the mitigation plan, which is defined during the risk treatment process (e.g. when the mitigation plan is to call an ambulance, the software automatically takes the action). At the same time, it also sends out emails and mobile phone messages to the safety officer, safety manager, project manager, site manager and any other related personnel. Secondly, after resolving the accident, there is a need to review the whole risk management processes, and all the information related to this accident will be input to the risk management database for future references. Furthermore, this risk will be highlighted when risk assessment is carried out for future project management.

\section{B. Introduction of Expert System}

A modern computer system is programmed to formalize the decision-making used by experts in a given field, like construction. As a result, in order to create an expert system, system designers must conduct interviews with the experts in the given field to determine the most appropriate reasoning processes to be used in decisionmaking processes. These rules, which comprise of logical If-Then statements, serve as the expert's knowledge base (Jablonowski, 1992). This decisionmaking expert system can be developed with the use of fuzzy logic technique, which is able to express the input results in degrees of positive or negative, and the system can accept the results that may be expressed in a "more or less" fashion rather than concrete number (Nick, 2009). According to Nick (2009), qualitative risk analysis process becomes more comprehensive with the use of fuzzy logic applications. Fuzzy logic makes certain that all complex variables related to the construction project are all considered during decisionmaking process. A fuzzy logic program is then quite suitable for performing qualitative risk analysis as it does not only accept human-style input like some typical logic program. This type of program allows project manager to take all the related information into account, giving each bit of information a differing level of importance, and not relying on only one criteria but on the whole situation

\section{CONCLUSIONS AND RECOMMENDATIONS}

More companies in the construction industry have been integrating risk management processes as part of their project management processes as the complexity in construction projects increases, making risk analytics more essential. Under the circumstances, use of risk management software may help the companies to achieve the successful integration. 
The literature review carried out for this study defined the relationship between the risk management framework and RMIS, emphasizing that an effective risk management framework should be established before the RMIS is implemented. Furthermore, it was proven that RMS plays an important role in managing risks and making decisions. As a result, the different types of RMS, which are commonly used in the market, were also analyzed and classified based on the study by NoakesFry (2003). It showed that there is a lack of RMS designed and developed with consideration of the specific features and functions of the construction industry.

The survey results also revealed that a majority of the respondents from construction firms in Singapore are using spreadsheet programs which are only effective for certain risk management processes like establishing context, reporting and presenting risk, assessing risk, and identifying risk. However, the software is ineffectual to carry out the risk management processes such as creating and performing risk avoidance plans, setting risk aversion level, controlling risk, performing risk retention, checking for residual risk and setting risk tolerance level, as they do not have the designed functions that are suitable to accomplish these processes. On the other hand, a minority of the respondents are using specific risk analysis software such as @Risk from Palisade Corporation, Crystal Ball from Decisioneering, and DecisionPro from Vanguard Software Corporation. This might be because the software does not cater specifically to the construction industry. Although, this type of software allows the user to control most of the aspects of the model's structure, definition and content, it heavily depends on the user's expertise to compute the resulting model in a more qualitative (industry-specific) aspect. Therefore, there is a need for industry-focused software packages that can facilitate more comprehensive qualitative as well as quantitative analyses. As a result, a possible management process algorithm for RMS was proposed in this study.

As this study concentrated solely on risk management, it could not consider the aspect that the risk management is part of project management. Although there are various types of software for risk management, it's difficult to separate the functions of the software apart from project management processes. Another limitation is that due to the small samples used for the analysis, the findings from this study may not be readily generalized and may lack a sufficient statistical power for detecting small, medium or possibly even large effects of the software investigated. Lastly, the findings need to be interpreted in the context of Singapore as all the respondents were from local companies in Singapore.

It is recommended to develop risk management software that can cater analyses specific to the characteristics of the construction industry. According to Nicks (2009a), risk management programs using Artificial Intelligence (AI) can offer more efficient risk analysis processes. Instead of relying on traditional inflexible rules designed in some typical RMS available in the current market, the AI based on fuzzy logic applications may better work for the industry as most computer-based logic programs perform analyses and make decisions, based on clear rules which are defined by software engineers. Also, integration of the Artificial Neural Networks with RMS would be one of the feasible solutions. Nicks (2009b) pointed out that neural networks are becoming a very useful tool in the business arena due to its ability that can reach to independent conclusions based on data provided, and then combine the conclusions to form a pattern for future use.

Lastly, apart from the issues of RMS, risk management personnel in the Singapore construction industry should try to adapt to new technologies and software which can assist them in performing risk management. They are encouraged to make use of RMIS, RMS and other technologies in managing risk for construction projects. This will be a starting point reducing the time for and complexity in risk management, improving the accuracy of risk analysis and prediction, and standardizing the information transferred in all the risk management processes.

\section{REFERENCES}

[1] G. Beekman, M.J. Quinn, "Tomorrow's Technology and You", US: Prentice Hall, United State, 2008.

[2] D.P. Duden, "From data to decisions: Selecting risk management software", Journal of Risk Management, vol. 43, no. 12, pp. 3335,1996

[3] D. Garson, 2008, "Student's T-Test of Difference of Means", Retrieved on December 09, 2009, from http://faculty.chass.ncsu.edu/garson/PA765/ttest.htm

[4] S. Heather, G. Danila, T. Evelyn, "RMIS: Taking Data Management Enterprisewide", Journal of Risk Management, vol. 52 , no. 10 , pp. 42-52, 2005.

[5] M. Jablonowski, "Expert Systems for Risk Management", Journal of Risk Management, vol. 39, no. 9, pp. 56-59, 1992.

[6] KPMG, 2006, "Singapore Risk Management Survey 2006", Retrieved on September 11, 2009, from http://www.kpmg.com.sg/publications/ras_RiskMgmtSurvey_200 6.pdf.

[7] M. Loosemore, J. Raftery, C. Reilly, D. Higgon, "Risk management for projects", NY: Tayor \& Francis, New York, 2006.

[8] Ministry of Manpower, 2006, "Risk Management", Retrieved on September 11, 2009, from

http://www.mom.gov.sg/publish/momportal/en/communities/wor kplace safety and health/maintaining a safe workplace/occupa tion safety/risk management.html.

[9] V. Nicks, 2009a, "A Neural Networks' Artificial Intelligence", Retrieved on September 11, 2009, from http://cognitivescience.suite101.com/article.cfm/a neural networ ks artificial intelligence\#tixzz0TYczRyQZ

[10] V. Nicks, 2009b, "Fuzzy Logic Improves Decision Support Software", Retrieved on September 11, 2009, from http://informatics.suite101.com/article.cfm/fuzzy logic improves _decision_support_software.

[11] K. Noakes-Fry, 2003, "Risk Analysis Software: Perspective", Retrieved on September 11, 2009, from http://www.njcu.edu/assoc/njcuitma/documents/addendums/Risk_ Analysis_Software_2.4.03.pdf.

[12] D.A. Olsen, "A new realm of risk management", Risk Management, vol. 42, no. 7, pp. 16-20, 1995.

[13] J.T. Protusada, 2008, "Advantages and Disadvantages of Microsoft Excel Database Application", Message posted to Pro- 
business Excel VBA Programming, Retrieved on September 11, 2009, from

http://msexcelvba.blogspot.com/2008/05/advantages-anddisadvantages-of.html.

[14] H. Roland, "Using IT to Drive Effective Risk Management", Risk Management, vol. 55, no. 1, pp. 43, 1998.

[15] C.A. Rowe, "Managing Risk in the Public Sector", Risk Management, vol. 51, no. 11, pp. 52, 2004.

[16] J. Shortreed, "ISO 31000 - Risk Management Standard", Institute for Risk Research, Otwa, Canada, 2008.

[17] N.J. Smith, T. Merna, P. Jobling, "Managing risk in construction projects", MA: Blackwell Pub, Malden, 2006.

[18] H.P. Tan, S. Sathish, "Information Systems Applications", McGraw-Hill, 2008.

[19] D.A. Tweedy, "Merging Information Systems for Risk and Benefits Managers", Risk Management, vol. 37, no. 11, pp. 64-68, 1990 . 